\title{
ANTIBACTERIAL ACTIVITY AND FLUORESCENCE PROPERTIES OF 4,7-DICHLORO-2-QUINOLINEMETHYLACRYLATE
}

\author{
HERNÁN VALLE ${ }^{a *}$, RAMALINGA VISWANATHAN MANGALARAJA ${ }^{a, b^{*}}$, LUIS AGUILAR $^{c, d}$, \\ CARLOS CARRASCO ${ }^{c}$, NATALIA PADILLA ${ }^{c}$, MOHAMED DAHROUCH ${ }^{e}$, BERNABÉ RIVAS $^{f}$ \\ AND HOMERO URRUTIA ${ }^{c, g}$ \\ ${ }^{a}$ Advanced Ceramics and Nanotechnology Laboratory, Department of Materials Engineering, Faculty of Engineering, University of Concepción, \\ Concepción 4070409, Chile. \\ ${ }^{b}$ Technological Development Unit (UDT), University of Concepción, Coronel Industrial Park, Coronel, Chile. \\ 'Biofilm and Environmental Microbiology Laboratory, Biotechnology Center, University of Concepción, P.O. Box 160-C, Concepción, Chile. \\ ${ }^{d}$ Environmental Science Faculty and Center EULA-Chile, University of Concepción, P.O. Box 160-C, Concepción, Chile. \\ ${ }^{e}$ Department of Organic Chemistry, Faculty of Chemical Sciences, University of Concepción, P.O. Box 160-C, Concepción, Chile. \\ ${ }^{f}$ Polymer Department, Faculty of Chemical Sciences, University of Concepción, Concepción 4089100, Chile. \\ ${ }^{g}$ Department of Microbiology, Faculty of Biological Sciences, University of Concepción, P.O. Box 160-C, Concepción, Chile.
}

\begin{abstract}
Currently, some quinoline-based anticancer drugs are successful repurposed for treatment of bacterial infections. This study assessed the antibacterial activity of the new anticancer compound 4,7-dichloro-2-quinolinemethylacrylate (AQM) against bacteria of both clinical and agricultural interest, and also determined the influence of some metal cations $\left(\mathrm{Fe}^{3+}, \mathrm{Mn}^{2+}, \mathrm{Zn}^{2+}, \mathrm{Na}^{+}, \mathrm{Mg}^{2+}, \mathrm{Co}^{2+}\right.$ and $\mathrm{Ni}^{2+}$ ) on the AQM photophysics. The synthesis of AQM was carried out by the reported method. The antibacterial activity of AQM on Pectobacterium carotovorum subsp. carotovorum (Pcc), Ralstonia solanacearum, Klebsiella pneuminiae, Pseudomonas syringae, Staphylococcus aureus y Bacillus sp., was evaluated using the spectrophotometric method of broth microdilution. At 125 ppm, AQM produced growth inhibition of 51.7\% in Pcc, and a bacteriostatic effect in S. aureus and Bacillus sp., but no effect was seen against the other bacteria. In addition, fluorescence quenching of $\mathrm{AQM}$ solution induced only by $\mathrm{Fe}^{3+}$ ion, and not by the other metal cations, was confirmed. These results postulate that AQM could be a molecule with potential application in antibacterial therapy or in the fluorometric detection of $\mathrm{Fe}^{3+}$ ions.
\end{abstract}

Keywords: Quinoline, antibacterial activity, fluorescence quenching, broth microdilution.

\section{INTRODUCTION}

A large number of quinoline-like molecules are known to have biological activities of pharmacological interest, such as: antimalarial, antiprotozoal, antifungal, anthelmintic, antiviral, antialzheimer, antipsychotic, antiasmatic, antiglaucoma, cardiotonic, anesthetic, anticancer, and especially, antibacterial. ${ }^{1-}$ ${ }^{4}$ The FDA has aproved 4-quinolones-like molecules (norfloxacin, ciprofloxacin and levofloxacine) $)^{5}$ and 8-hydroxyquinolines-like molecules (clioquinol and nitroxoline $)^{6,7}$ for use in pharmaceutical trials in humans. The mechanisms of action of 4-quinolones and 8-hydroxyquinolines against bacteria have been previously reported. The 4-quinolones inhibit the topoisomerase enzyme, whose main function is to unwind the double strand of bacterial DNA allowing the ribosome to advance during the genome replication and, therefore, the interruption of this process causes the bacterial death., ${ }^{5,-10}$ For the 8hydroxyquinolines, some research suggest that the antibacterial effect of these molecules is due to their high chelating capacity of divalent cations $\left(\mathrm{Mg}^{2+}, \mathrm{Mn}^{2+}\right.$, $\mathrm{Ca}^{2+}$ ) that allow them to bind to metal cofactors of bacterial enzymes and, consequently, inhibit the enzymatic activity. ${ }^{7,11}$ Other types of quinoline-like molecules with antibacterial activity, which contain various functional chemical groups, are discovered year after year, but not all of them are submitted to the FDA for pre-clinical studies. ${ }^{3,12-14}$

Several studies have reported that some quinoline-like molecules with antibacterial activity can be used as new anticancer agents, either by administering them individually or in combination with another conventional anticancer drug. Some examples of the latter are: nitroxoline, ${ }^{15-18}$ clioquinol, ${ }^{19,20}$ iodoquinol, oxyquinoline, ${ }^{21}$ bedaquiline, ${ }^{22,23}$ ciprofloxacin and levofloxacin. ${ }^{23}$ On the other hand, there are also some reports of quinoline-based anticancer drugs used successfully as treatment for bacterial infections (e.g., camptothecin derivatives). ${ }^{24}$ This double biological activity is probably due to the similarity of certain biochemical processes of human and bacterial cells (e.g., cell division or cellular respiration) in which structurally similar biomolecules participate, which would be the therapeutic target for these quinolinic drugs. ${ }^{8}$

It is noteworthy that Valle et al. recently reported the synthesis of the new molecule AQM, which showed potent cytotoxic activity against breast carcinoma cells MDA-MB-453 ( $\left(\mathrm{IC}_{50}: 19 \mu \mathrm{M}\right),{ }^{25}$ however, its potential antibacterial activity has not been evaluated. In the present work, we investigated the antibacterial activity of AQM on six bacterial species, two pathogenic bacteria for humans
(Klebsiella pneuminiae and Staphylococcus aureus), three phytopathogenic bacteria (Pcc, Ralstonia solanacearum and Pseudomonas syringae) and Bacillus $s p$. In addition, some fluorescence properties of AQM were examined in tetrahydrofuran.

\section{EXPERIMENTAL SECTION}

\subsection{Reagents and Materials}

To AQM's synthesis the following reagents were used without further purification: 3-chloroaniline, ethyl acetoacetate, phosphorus oxychloride $\left(\mathrm{POCl}_{3}\right)$, benzoyl chloride (Bz-Cl), acryloyl chloride, triethylamine (TEA), diphenyl ether, n-hexane, ethanol, methanol, diethyl ether, dichloromethane (DCM), ethyl acetate (AcOEt), tetrahydrofuran (THF), sodium hydroxide $(\mathrm{NaOH})$, hydrochloric acid $(\mathrm{HCl}, 37 \% \mathrm{v} / \mathrm{v})$, sodium bicarbonate $\left(\mathrm{NaHCO}_{3}\right)$, sodium sulfate anhydrous $\left(\mathrm{Na}_{2} \mathrm{SO}_{4}\right)$ and 3-chloroperbenzoic acid (3-CPBA, 72\% w/w). The analytical grade nitrate salts: $\mathrm{Zn}\left(\mathrm{NO}_{3}\right)_{2} \cdot 6 \mathrm{H}_{2} \mathrm{O}, \mathrm{Ni}\left(\mathrm{NO}_{3}\right)_{2} \cdot 6 \mathrm{H}_{2} \mathrm{O}$, $\mathrm{Mg}\left(\mathrm{NO}_{3}\right)_{2} \cdot 6 \mathrm{H}_{2} \mathrm{O}, \quad \mathrm{Co}\left(\mathrm{NO}_{3}\right)_{2} \cdot 6 \mathrm{H}_{2} \mathrm{O}, \quad \mathrm{Mn}\left(\mathrm{NO}_{3}\right)_{2} \cdot \mathrm{xH}_{2} \mathrm{O}, \quad \mathrm{Fe}\left(\mathrm{NO}_{3}\right)_{3} \cdot 9 \mathrm{H}_{2} \mathrm{O}$ and $\mathrm{NaNO}_{3}$, were employed as sources of metal cations for the fluorescence quenching measurements. All reagents were supplied by Merck, except 3-CPBA and nitrate salts, which were provided by Acros Organic and Sigma-Aldrich, respectively. Double-distilled water (DDW) was used throughout all experiments.

Merck silica gel $60 \mathrm{~F}_{254}$-coated aluminium plates $(10 \times 5 \mathrm{~cm})$, n-hexane-ethyl acetate (1:1), and an ultraviolet lamp (CAMAG, 254 and $366 \mathrm{~nm}$ ) were used to assess the purity of the compounds by thin layer chromatography (TLC). Flash column chromatography was conducted over Merck silica gel 60 (0.063-0.200 $\mathrm{mm} / 70-230$ mesh ASTM).

\subsection{Synthesis of 4,7-dichloroquinaldine}

In a $2000-\mathrm{mL}$ round bottom flask $418.6 \mathrm{~mL}$ of 3 -chloroaniline (4 mol), 510.6 $\mathrm{mL}$ of ethyl acetoacetate $(4 \mathrm{~mol}), 2 \mathrm{~mL}$ of $\mathrm{HCl}(37 \% \mathrm{v} / \mathrm{v})$ and $166 \mathrm{~g}$ of anhydrous $\mathrm{Na}_{2} \mathrm{SO}_{4}$, were mixed in that order. Then the container was sealed and maintained under magnetic stirring for 72 hours at $25{ }^{\circ} \mathrm{C}$. Subsequently, the insoluble $\mathrm{Na}_{2} \mathrm{SO}_{4}$ was separated by decantation and the supernatant was filtered under vacuum using filter paper (Whatman $\mathrm{N}^{\circ} 2$ ). $812 \mathrm{~mL}$ of a translucent yellow oily liquid were obtained (crude ethyl $\beta$-(3-chloroanilino)crotonate). 
In other 2000-mL round bottom flask equipped with condenser, dropping funnel and thermometer, $1000 \mathrm{~mL}$ of diphenyl ether were heated to $250{ }^{\circ} \mathrm{C}$ under stirring, using a heating mantle with built-in magnetic stirrer. $200 \mathrm{~mL}$ of the yellow oil of the first step (crude ethyl $\beta$-(3-chloroanilino)crotonate), contained in the dropping funnel, were added dropwise into the hot diphenyl ether $\left(250{ }^{\circ} \mathrm{C}\right)$ over a period of $0.5 \mathrm{~h}$ and both heating and stirring were continued for an additional $10 \mathrm{~h}$. After this time the reaction mixture was allowed to cool to $60{ }^{\circ} \mathrm{C}$ and the solid formed was filtered under vacuum, washed with abundant $n$-hexane until all residual diphenyl ether was removed, and thoroughly dried in the oven at $60{ }^{\circ} \mathrm{C}$. $45 \mathrm{~g}$ of a beige powder was obtained (crude 7-chloro-4hydroxyquinaldine)

Subsequently, in a $250-\mathrm{mL}$ round bottom flask equipped with a condenser, a mixture of $90 \mathrm{~mL}$ of $\mathrm{POCl}_{3}$ and $45 \mathrm{~g}$ of crude 7-chloro-4-hydroxyquinaldine was heated at $100{ }^{\circ} \mathrm{C}$ under constant stirring. The reaction mixture was cooled to room temperature, slowly poured into ice-water $(500 \mathrm{~mL})$ and basified with $4 \mathrm{M}$ $\mathrm{NaOH}$ to $\mathrm{pH} 8$. The solid produced was triturated, washed with water, filtered under vacuum and dried at $60{ }^{\circ} \mathrm{C}$; It was then dissolved in DCM and purified by flash chromatography on silica gel $60(0.063-0.200 \mathrm{~mm})$ using DCM as eluent. The elute was concentrated in vacuo to give a white-yellowish solid ( $28 \mathrm{~g})$, which was recrystallized from ethanol-water to obtain $25.5 \mathrm{~g}$ of white needle-shaped crystals, identified by ${ }^{1} \mathrm{H}$ NMR spectroscopy as 4,7-dichloroquinaldine.

\subsection{Synthesis of 4,7-dichloro-2-quinolinemethylbenzoate (2QMB)}

To a solution of 4,7-dichloro-quinaldine $(25.03 \mathrm{~g}, 118 \mathrm{mmol})$ in dichloromethane $(200 \mathrm{~mL})$ was added 3-CPBA (24.85 g, $144 \mathrm{mmol})$. The reaction mixture was heated at $60^{\circ} \mathrm{C}$ for $6 \mathrm{~h}$ under magnetic stirring and then washed with saturated aqueous $\mathrm{NaHCO}_{3}(400 \mathrm{~mL})$. The dichloromethane layer was dried over $\mathrm{Na}_{2} \mathrm{SO}_{4}$ and the solvent evaporated in vacuo to give 4,7dichloroquinaldine-N-oxide (NOQ) as a yellowish white powder, which was used without further purification. To a solution of NOQ $(25 \mathrm{~g}, 110 \mathrm{mmol})$ in dichloromethane $(300 \mathrm{~mL})$ was added benzoyl chloride $(15 \mathrm{~mL}, 129 \mathrm{mmol})$, mixed, and then heated at $60^{\circ} \mathrm{C}$ under nitrogen atmosphere for $18 \mathrm{~h}$. After this period, the reaction mixture was cooled to room temperature and washed with 1 $\mathrm{M} \mathrm{NaOH}$ aqueous solution $(2 \times 300 \mathrm{~mL})$, followed by brine washing $(300 \mathrm{~mL})$, $\mathrm{Na}_{2} \mathrm{SO}_{4}$ drying, and concentration under vacuum to obtain a solid residue (2QMB), which was recrystallized from hot methanol.

\subsection{Synthesis of 4,7-dichloro-2-quinolinemethanol (QM)}

To a solution of 2QMB $(17 \mathrm{~g}, 50 \mathrm{mmol})$ in $82 \% \mathrm{v} / \mathrm{v}$ acetone aqueous $(1000$ $\mathrm{mL})$ was added a solution of $\mathrm{NaOH}(4 \mathrm{~g}, 100 \mathrm{mmol})$ in water $(20.4 \mathrm{~mL})$. The reaction mixture was stirred at $35^{\circ} \mathrm{C}$ for $1 \mathrm{~h}$, before further water was added $(500$ $\mathrm{mL}$ ). The $\mathrm{pH}$ of the mixture was adjusted to $\sim 7$ with $6 \mathrm{M} \mathrm{HCl}$. The mixture was concentrated to half the volume under vacuum, and subsequently extracted with DCM $(2 \times 200 \mathrm{~mL})$. The combined organic layers were washed with brine, dried over $\mathrm{Na}_{2} \mathrm{SO}_{4}$, and concentrated by vacuum distillation to obtain a solid (QM), which was washed with diethyl ether.

\subsection{Synthesis of 4,7-dichloro-quinolinemethyl acrylate (AQM)}

QM $(9 \mathrm{~g}, 40 \mathrm{mmol})$ and triethylamine $(33.3 \mathrm{~mL}, 240 \mathrm{mmol})$ dissolved in 900 $\mathrm{mL}$ of anhydrous THF were placed in a round-bottomed, three-necked flask equipped with a dropping funnel. Then $9.7 \mathrm{~mL}$ of acryloyl chloride $(120 \mathrm{mmol})$ diluted with $57 \mathrm{~mL}$ of THF were added dropwise into the mixture, under nitrogen atmosphere and with stirring at $10^{\circ} \mathrm{C}$. The reaction was allowed to proceed at room temperature for $3 \mathrm{~h}$, and the reaction mixture was then partitioned between $5 \% \mathrm{w} / \mathrm{v} \mathrm{NaHCO}_{3}$ aqueous $(500 \mathrm{~mL})$ and AcOEt $(500 \mathrm{~mL})$. The aqueous phase was re-extracted with AcOEt $(500 \mathrm{~mL})$ and the combined organic phases washed with water $(500 \mathrm{~mL})$, dried over $\mathrm{Na}_{2} \mathrm{SO}_{4}$ and concentrated until dryness under vacuum distillation to give the solid product, $\mathrm{AQM}$.

\subsection{Spectroscopic characterization}

A NMR Bruker Ascend ${ }^{\mathrm{TM}} 400 \mathrm{MHz}$ spectrometer, chloroform- $d\left(\mathrm{CDCl}_{3}, 98 \%\right.$, Sigma-Aldrich) or dimethyl sulfoxide- $d_{6}$ (DMSO- $d_{6}, 99.96 \%$, MagniSolve ${ }^{\mathrm{TM}}$ ) and NMR sample tubes were used to elucidate the structure of compounds (obtained from each synthesis step of AQM) by proton NMR (400 MHz) and/or carbon-13 NMR (100 MHz) techniques. Each synthetized compound was dissolved in deuterated solvent at a concentration of $30 \mathrm{mg} \mathrm{mL}^{-1}$. UV absorption spectrum of AQM in THF solution was recorded at room temperature using a
Shimadzu UV-2600 spectrophotometer (with quartz cuvette of $1 \times 1 \mathrm{~cm}$ and 0.2 $\mathrm{nm}$ absorbance slit width), which was controlled by Shimadzu UVProbe software.

\subsection{Fluorescence quenching measurements}

The fluorescence quenching ability of different metal ions $\left(\mathrm{Zn}^{2+}, \mathrm{Ni}^{2+}, \mathrm{Mg}^{2+}\right.$, $\mathrm{Co}^{2+}, \mathrm{Mn}^{2+}, \mathrm{Fe}^{3+}$ and $\mathrm{Na}^{+}$) onto the AQM solution was investigated. Firstly, all the metal ions were dissolved in water (DDW) at $100 \mathrm{mM}$ concentration. Then $45.4 \mu \mathrm{L}$ of metal ion solution was added into a $5 \mathrm{~mL}$ of $2.42 \mathrm{mM} \mathrm{AQM}$ solution (in THF) at ambient temperature, resulting a metal ion concentration about 0.9 $\mathrm{mM}$ in the AQM solution. The metal ions able to quench inherent fluorescence from AQM solution were studied as quenchers at various concentrations $(0.05-$ $0.9 \mathrm{mM}$ ) by fluorescence spectroscopy. The fluorescence spectra of AQM and their respective AQM-metal ion complex (in THF solution) were measured on a Photon Technology International (PTI) Quantamaster fluorometer (with quartz cuvette of $1 \times 1 \mathrm{~cm}$ and $5 \mathrm{~nm}$ excitation and emission slit widths), which was controlled by PTI FelixGX software (version 4.0.2).

\subsection{Antibacterial Assay}

The six bacterial isolates, two pathogenic bacteria for humans (Klebsiella pneumoniae and Staphylococcus aureus), three phytopathogenic bacteria (Pcc, Ralstonia solanacearum and Pseudomonas syringae) and Bacillus sp., were supplied from the Biofilm and Environmental Microbiology Laboratory (Center of Biotechnology) of University of Concepción. All the bacterial were maintain routinely on Tripticase Soy Broth (TBS).

A modified broth microdilution method based on the National Committee for Clinical Laboratory Standards guidelines ${ }^{26}$ was used to assess the antibacterial activity of AQM against the bacterial strains. AQM stock solution of $2500 \mathrm{ppm}$ was prepared using 10\% DMSO-TSB as solvent, and further ten-fold serial diluted in 5 steps using TSB to produce dilutions of $1: 10^{1}$ to $1: 10^{5}$. From an overnight culture, a bacterial suspension was adjusted to a concentration of $\sim 1 \times 10^{8} \mathrm{CFU} \mathrm{mL} \mathrm{mL}^{-1}$ (0.5 McFarland standard), and then diluted to $1: 10^{2}$ into TSB. Briefly, $80 \mu \mathrm{L}$ of TSB was added into wells of a 96 -well microtiter plate. To these, $100 \mu \mathrm{L}$ of each AQM ten-fold serial dilutions was separately added, followed by the addition of $20 \mu \mathrm{L}$ of the bacterial suspension. Thus, the AQM final concentrations were: $125,12.5,1.25,0.125$ and $0.0125 \mathrm{ppm}$, while the bacterial final concentration was about $1 \times 10^{5} \mathrm{CFU} \mathrm{mL}^{-1}$ in each well. To test if DMSO has an antibacterial activity, solutions containing DMSO dissolved in TSB at $0.5,0.05,0.005,0.0005$, and $0.00005 \%$ were prepared to use as control. Afterward, the growth of bacteria at $37^{\circ} \mathrm{C}$ was measured in terms of optical density at $600 \mathrm{~nm}$ (OD600), during $\sim 20 \mathrm{~h}$ at 1-hour intervals, using an automated plate reader TECAN Infinite Pro 2000. A mild and discontinuous agitation for $10 \mathrm{~s}$ before the measurement was carried out. The antibacterial rate (AR) was calculated according the following equation:

$$
\operatorname{AR}(\%)=\frac{(\mathrm{OD} \text { test }-\mathrm{OD} \text { blank })}{\text { OD control }} \times 100
$$

Where "OD test" is OD600 value from the well with AQM plus bacteria plus culture medium; "OD blank" is OD600 value from the well with AQM plus culture medium (without bacteria); and "OD control" is OD600 value from the well with bacteria plus culture medium.

To assess the bactericidal activity of AQM, sub-cultures were prepared by transferring $100 \mu \mathrm{L}$ from the wells with treatment to $5 \mathrm{~mL}$ of culture medium without $\mathrm{AQM}$ and allowed to grow for $24 \mathrm{~h}$, verifying the growth of bacteria by presence or absence of turbidity. All experiments were carried out in triplicate.

\section{RESULTS AND DISCUSSION}

\subsection{Synthesis of AQM}

The synthesis procedure for obtaining AQM and some of its precursors, such as 4,7-dichloroquinaldine, $2 \mathrm{QMB}$ and $\mathrm{QM}$, is shown in Scheme 1. Step [a] for the synthesis of 4,7-dichloroquinaldine (59\% yield) involved three reactions: an acid-catalyzed condensation of 3-chloroaniline with ethyl acetoacetate to form ethyl $\beta$-(3-chloroanilino)crotonate, followed by its thermal cyclization in diphenyl ether under reflux conditions (Conrad-Limpach method), and subsequent chlorination of the intermediate 7-chloro-4-hydroxyquinaldine with 
$\mathrm{POCl}_{3}{ }^{27}$ In step [b], 4,7-dichloroquinaldine is first converted into its corresponding N-oxide by reaction with 3 -CPBA ( $92 \%$ yield), and then is transformed into its $\mathrm{N}$-benzoyloxy derivative by consecutive reaction with $\mathrm{Bz}$ $\mathrm{Cl}$, followed by rearrangement of the benzoyloxy group from $\mathrm{N}-1$ to the $\mathrm{C}-2$ methyl group to form $2 \mathrm{QMB}$ ester ( $48 \%$ yield). ${ }^{28}$

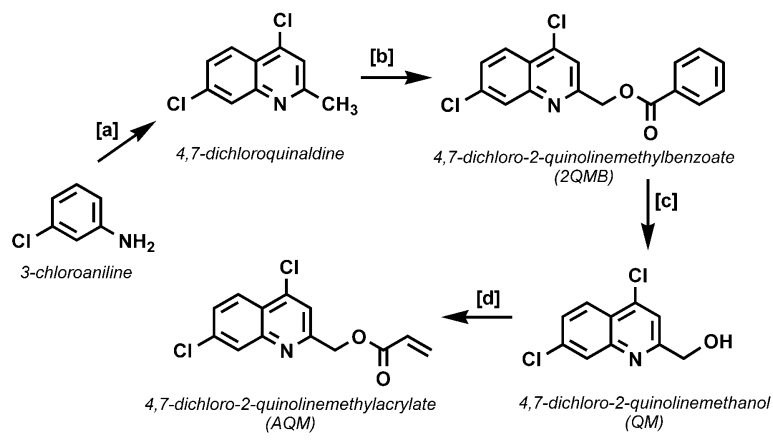

[a] 1) ethyl acetoacetate, $\mathrm{Na}_{2} \mathrm{SO}_{4}, 25^{\circ} \mathrm{C}, 72 \mathrm{hrs}$, 2) diphenyl ether, $250^{\circ} \mathrm{C}, 10 \mathrm{hrs}$, 3) $\mathrm{POCl}_{3}, 100^{\circ} \mathrm{C}, 15 \mathrm{~min}$ [b] 1) 3-chloroperbenzoic acid, DCM, reflux, $6 \mathrm{hrs}$, 2) benzoyl chloride, DCM, $\mathrm{N}_{2}$, reflux, $18 \mathrm{hrs}$. [c] $\mathrm{NaOH}$, acetone $/ \mathrm{H}_{2} \mathrm{O}, 35^{\circ} \mathrm{C}, 1 \mathrm{hr}$

[d] acryloyl chloride, $\mathrm{THF}$, triethylamine, $25^{\circ} \mathrm{C}, 3 \mathrm{hrs}$

Scheme 1. Synthesis of AQM.

In step [c] 2QMB ester underwent basic hydrolysis to produce the $\mathrm{QM}$ alcohol (60\% yield). Finally, in step [d], the esterification of QM with acryloyl chloride is performed to produce AQM (95\% yield). The overall yield of the AQM synthesis (calculated based on 3-chloroaniline) was $15 \%$. Its ${ }^{1} \mathrm{H}$ NMR spectrum in DMSO- $d_{6}$ (Figure 1) shows four aromatic proton signals designated as $\boldsymbol{a}, \boldsymbol{b}, \boldsymbol{c}$ and $\boldsymbol{d}$, which are located in the region between $\delta \mathrm{H} 8.20-7.70$. The doublet signal at $\delta \mathrm{H} 8.16$ with ortho-coupling of $9.0 \mathrm{~Hz}$ is attributed to $\boldsymbol{b}$, and the doublet signal at $\delta \mathrm{H} 8.07$ with meta-coupling of $2.1 \mathrm{~Hz}$ is assignated to $\boldsymbol{d}$. Meanwhile, $\boldsymbol{c}$ corresponds to the double-doublet signal at $\delta \mathrm{H} 7.75$ with ortho- and metacoupling of 9.0 and $2.1 \mathrm{~Hz}$ respectively, confirming the position of one chlorine atom at C-7. The singlet signal appearing at $\delta \mathrm{H} 7.80$ is attributed to $\boldsymbol{a}$. A second region of signals between $\delta \mathrm{H} 6.00$ and 6.50 belongs to the three vinyl protons designated as $\boldsymbol{f}, \boldsymbol{g}$ and $\boldsymbol{h}$. The $\boldsymbol{h}$ signal corresponds to the double-doublet centred at $\delta \mathrm{H} 6.45$ with trans- and geminal-coupling of $17.3 \mathrm{~Hz}$ and $1.6 \mathrm{~Hz}\left({ }^{3} J_{h f}\right.$ and $\left.{ }^{2} J_{h g}\right)$ respectively.

The signal for $f$ at $\delta \mathrm{H} 6.33$ is also a double-doublet, but with trans- and ciscoupling of $17.3 \mathrm{~Hz}$ and $10.2 \mathrm{~Hz}\left({ }^{3} J_{h f}\right.$ and $\left.{ }^{3} J_{g f}\right)$; and the signal for $g$ at $\delta \mathrm{H} 6.04$ is again a double-doublet, this time with geminal- and cis-coupling of $1.6 \mathrm{~Hz}$ and $10.2 \mathrm{~Hz}\left({ }^{2} J_{h g}\right.$ and $\left.{ }^{3} J_{g f}\right)$ respectively. Finally, the singlet at $\delta \mathrm{H} 5.40$ is attributed to the two $\boldsymbol{e}$ protons of the methylene group that connects both the quinoline ring and acrylic moiety.

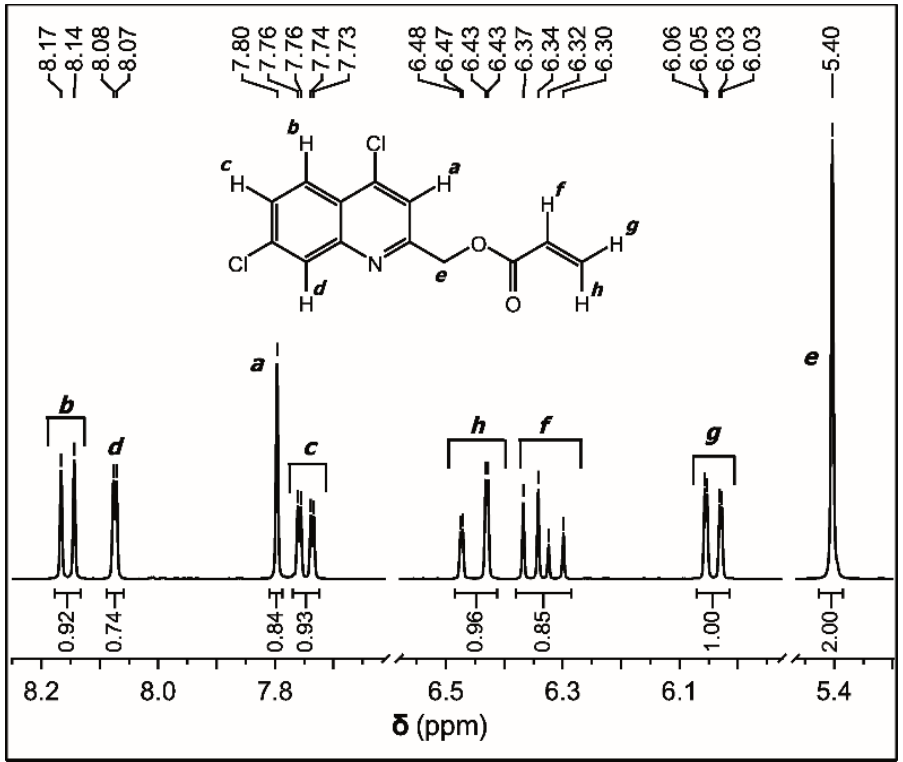

Figure 1. ${ }^{1} \mathrm{H}$ NMR spectrum of AQM in DMSO-d $\mathrm{d}_{6}$.
Additionally, ${ }^{13} \mathrm{C}$ NMR spectrum of AQM (Figure S1, supporting information) shows signals for: (1) six quaternary carbons of which five are aromatics (C-2, C-4, C-7, C-9 and C-10, between $\delta 120$ and 160) and one is from a ester carbonyl group (C-11, at $\delta 165.11)$, (2) four aromatic methine carbons (C-3, C-5, C-6 and C-8, between $\delta 119$ and 128), (3) two olefinic carbons (C-12 and C-13, between $\delta 128$ and 133), and (4) one methylene carbon (C-1, at $\delta 65.99)$. Both the ${ }^{1} \mathrm{H}$ NMR and ${ }^{13} \mathrm{C}$ NMR (in DMSO- $d_{6}$ ) spectra of AQM show all of the signals matching with the expected structure. On the other hand, structural elucidation of compounds 4,7-dichloroquinaldine, 2QMB and QM was performed based on the analysis of ${ }^{1} \mathrm{H}$ NMR spectra shown in Figures S2-S4 (in supporting information) and by comparing of these spectral data with those reported in literature. AQM and 2QMB are new molecules, however, 4,7-dichloroquinaldine and QM have been reported by Singh et al. $^{27}$ and Esparza-Ruiz et al. ${ }^{29}$ respectively.

\subsection{Photophysics properties of AQM in THF solution}

The fluorescence emission and UV-visible absorption spectra of AQM in THF solution are shown in Figure 2. The UV-visible spectrum exhibited a pronounced absorption maximum peak at $324 \mathrm{~nm}$ that corresponds to the $\pi-\pi^{*}$ transition of quinoline group. In the fluorescence spectrum, the emission maximum was observed around $409 \mathrm{~nm}$ when excited at $324 \mathrm{~nm}$. The difference between the absorption $\left(\lambda_{\mathrm{A}}=324 \mathrm{~nm}\right)$ and emission $\left(\lambda_{\mathrm{F}}=409 \mathrm{~nm}\right)$ maximum wavelengths (expressed in wavenumbers, $\mathrm{cm}^{-1}$ ) is known as Stokes shift, an important parameter which provides information about structure and properties between the ground $\mathrm{S}_{0}$ state and the first excited $\mathrm{S}_{1}$ state of the fluorophores. ${ }^{30}$ The calculated value of Stokes shift for AQM is $6320 \mathrm{~cm}^{-1}$, a relatively large value which could be attributed to the change in the electron density of the compound upon excitation. The fluorescence quantum yield $\left(\Phi_{\mathrm{F}}\right)$ is the ratio of the number of emitted photons to the number of absorbed photons by the fluorophore molecules, and is calculated using the following equation:

$$
\Phi_{\mathrm{F}}^{\mathrm{x}}=\Phi_{\mathrm{F}}^{\mathrm{r}} \frac{\mathrm{S}_{\mathrm{x}}}{\mathrm{S}_{\mathrm{r}}} \frac{\mathrm{A}_{\mathrm{r}}}{\mathrm{A}_{\mathrm{x}}} \frac{\mathrm{n}_{\mathrm{x}}^{2}}{\mathrm{n}_{\mathrm{r}}^{2}}
$$

Where the designators $\mathrm{x}$ and $\mathrm{r}$ indicate sample and reference, respectively, $\Phi_{\mathrm{F}}$ is the fluorescence quantum yield, $\mathrm{A}$ is the absorbance intensity, $\mathrm{S}$ is the integrated emission area and $\mathrm{n}$ is the solvent refractive index. The $\Phi_{\mathrm{F}}$ value of $\mathrm{AQM}$ in THF, calculated by above equation, is 0.101 by using pyrene in THF $\left(\Phi_{\mathrm{F}}=0.79\right)$ as standard reference. ${ }^{31}$.

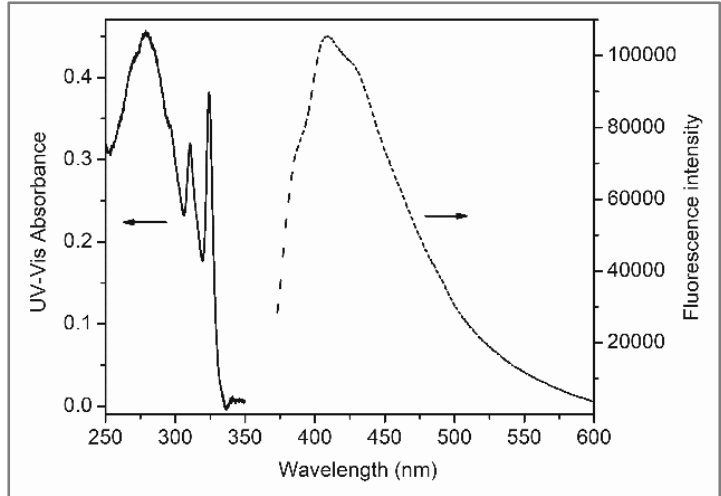

Figure 2. Normalized absorption and fluorescence emission spectra of AQM in THF at a concentration of $100 \mu \mathrm{M}$.

\subsection{Influence of metal cations on the AQM photophysics}

The metal cations $\mathrm{Fe}^{3+}, \mathrm{Mn}^{2+}, \mathrm{Zn}^{2+}, \mathrm{Na}^{+}, \mathrm{Mg}^{2+}, \mathrm{Co}^{2+}$ and $\mathrm{Ni}^{2+}$ are essential for bacterial growth. The effect of these metal cations on the fluorescence emission of AQM in THF solution, was determined by measuring of the values of relative fluorescence intensity $\left(\mathrm{I} / \mathrm{I}_{0}\right)$, defined as the ratio between fluorescence intensities (at maximum emission peak, $\lambda_{\mathrm{F}}=409 \mathrm{~nm}$ ) after and before addition of metal cations to the AQM solution. As shown in Figure 3, the relative fluorescence intensity $\left(\mathrm{I} / \mathrm{I}_{0}\right)$ suddenly decreased with the addition of $\mathrm{Fe}^{3+}$, while the other tested cations $(0.9 \mathrm{mM})$ did not markedly change the relative fluorescence intensity, thus it can be concluded that this system is selective for $\mathrm{Fe}^{3+}$. 

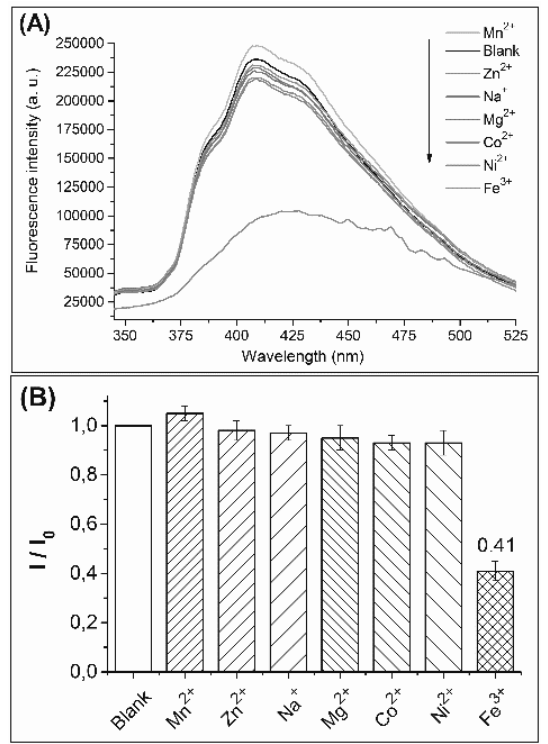

Figure 3. Fluorescence quenching of AQM in THF solution by the addition of different metal cations dissolved in water $\left(\lambda_{\mathrm{ex}}=324 \mathrm{~nm}\right.$, the concentrations of $\mathrm{AQM}$ and metal cation are $2.4 \mathrm{mM}$ and $0.9 \mathrm{mM}$, respectively). Each experiment was done in duplicate.

Figure 4A shows the fluorescence spectrum intensity of AQM solution decreasing as $\mathrm{Fe}^{3+}$ concentration increases. Moreover in Figure 4B, a linear relationship between the fluorescence quenching $\left(\mathrm{I}_{0} / \mathrm{I}\right)$ and the $\mathrm{Fe}^{3+}$ concentration is observed between 0.05 and $0.9 \mathrm{mM}$, which is consistent with the Stern-Volmer equation ${ }^{30}$ and, therefore, suitable for the quantification of $\mathrm{Fe}^{3+}$ in this range of concentrations. From the Stern-Volmer equation, $I_{0} / I=1+K_{s v}[Q]$, the $K_{s v}$ constant was calculated, which represents the efficiency of the fluorescence quenching. The others terms in the equation are the quencher concentration, [Q], and the maximum fluorescence intensities of the AQM solution in the absence and presence of $\mathrm{Fe}^{3+}$ (quencher), $\mathrm{I}_{0}$ and I, respectively. The $\mathrm{K}_{\mathrm{sv}}$ value obtained of $\mathrm{AQM}$ for $\mathrm{Fe}^{3+}$ was $1.62 \times 10^{3} \mathrm{M}^{-1}$, indicating that this compound has a moderate sensitivity for $\mathrm{Fe}^{3+}$ ion in comparison to others compounds such as julolidine derivatives $\left(3.3 \times 10^{4} \mathrm{M}^{-1}\right)^{32}$ and rhodamine derivatives $\left(2.46 \times 10^{4} \mathrm{M}^{-1}\right){ }^{33}$ This result is indicative of a possible iron (III) chelating activity of AQM which leads to a significant fluorescence quenching of the AQM solution. ${ }^{34,35}$
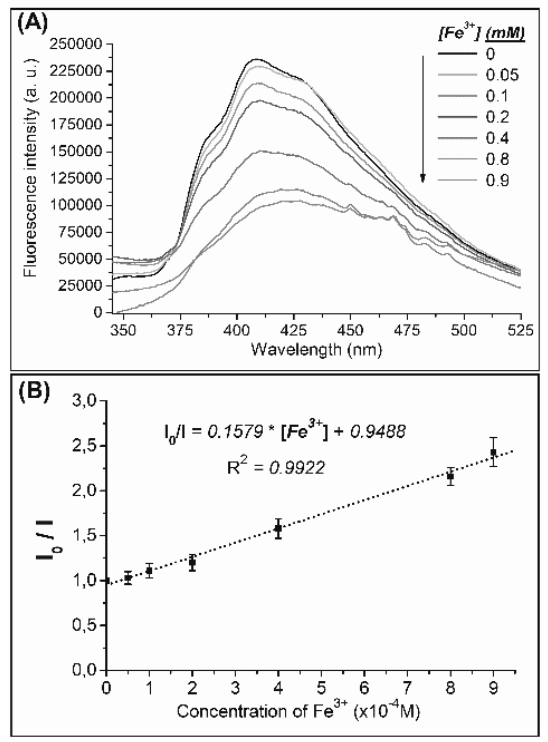

Figure 4. (A) Fluorescence emission spectra of AQM in THF solution at various concentrations of $\mathrm{Fe}^{3+}$ cation $\left(\lambda_{\mathrm{ex}}=324 \mathrm{~nm}\right)$. (B) Linear relationship between the relative fluorescence quenching of $\mathrm{AQM}$ and the $\mathrm{Fe}^{3+}$ concentration. The AQM concentration was held at $2.4 \mathrm{mM}$. Each point in (B) represent the mean \pm standard deviation (SD) of three independent experiments.

\subsection{Antibacterial Assay}

The cultures of Ralstonia solanacearum, Klebsiella pneuminiae and Pseudomonas syringae treated with AQM at a concentration of $125 \mathrm{ppm}$ (Figures 5-7) produced OD600 values similar to those of the respective culture without treatment (blank - DMSO) within the time range tested, indicating absence of antibacterial effect. On the other hand, the cultures of Staphylococcus aureus and Bacillus sp. treated with AQM at the same concentration (Figures 8 and 9) produced near-zero and constant OD600 values during the 20 hours of treatment, which demonstrates the antibacterial effect of AQM on these Gram-positive bacteria. The bactericidal assay showed that AQM has not bactericidal effect on the bacterial strains in the range of tested concentrations, this indicating a bacteriostatic effect of this molecule. As regards Pcc bacteria subjected to the same treatment (AQM at $125 \mathrm{ppm}$ ), the OD600 values trend in Figure 10 showed a reduction in the growth rate during the first 14 hours (probably associated with a prolonged Lag phase), followed by a stationary phase until the end of experiment.

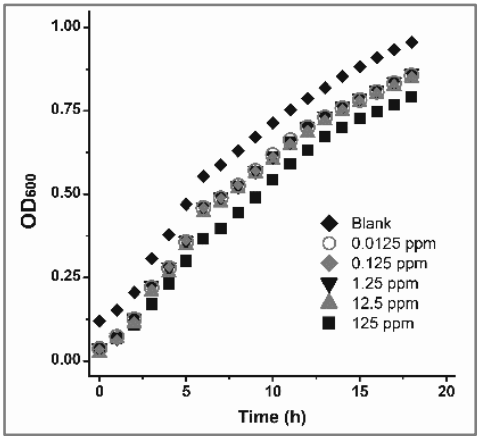

Figure 5. Antimicrobial effect of the AQM molecule on $R$. solanacearum. OD600 is optical density at $600 \mathrm{~nm}$. Each point presents the mean of three measurements. The SD bars were deleted for clarity.

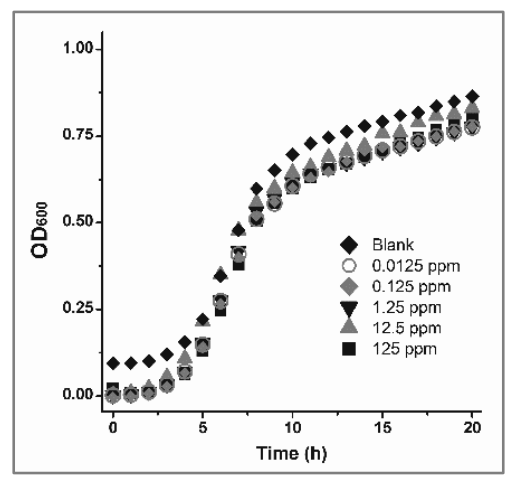

Figure 6. Antimicrobial effect of the AQM molecule on $K$. pneumoniae. OD600 is optical density at $600 \mathrm{~nm}$. Each point presents the mean of three measurements. The SD bars were deleted for clarity.

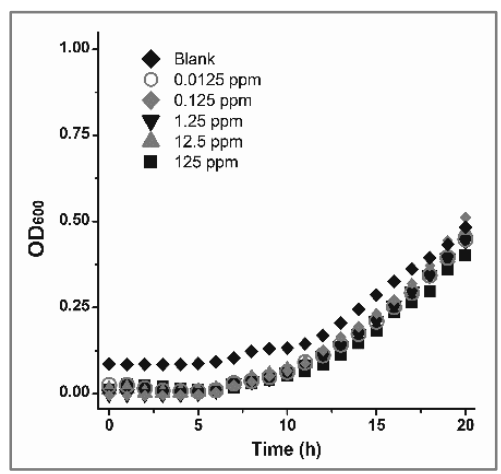

Figure 7. Antimicrobial effect of the AQM molecule on P. syringae. OD600 is optical density at $600 \mathrm{~nm}$. Each point presents the mean of three measurements. The SD bars were deleted for clarity. 


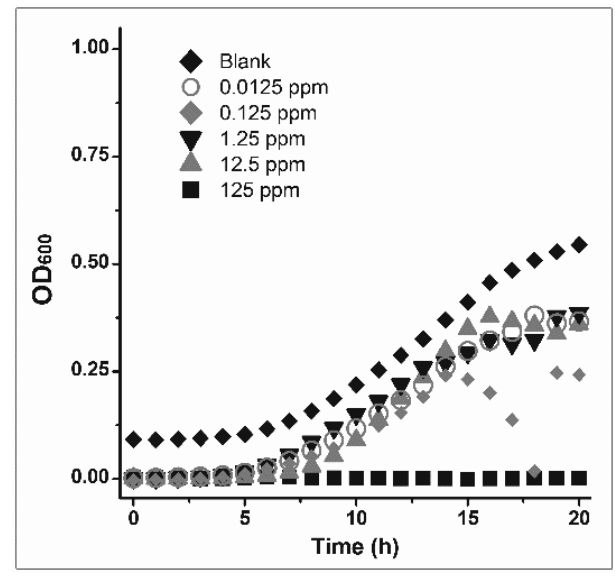

Figure 8. Antimicrobial effect of the AQM molecule on S. aureus. OD600 is optical density at $600 \mathrm{~nm}$. Each point presents the mean of three measurements. The SD bars were deleted for clarity.

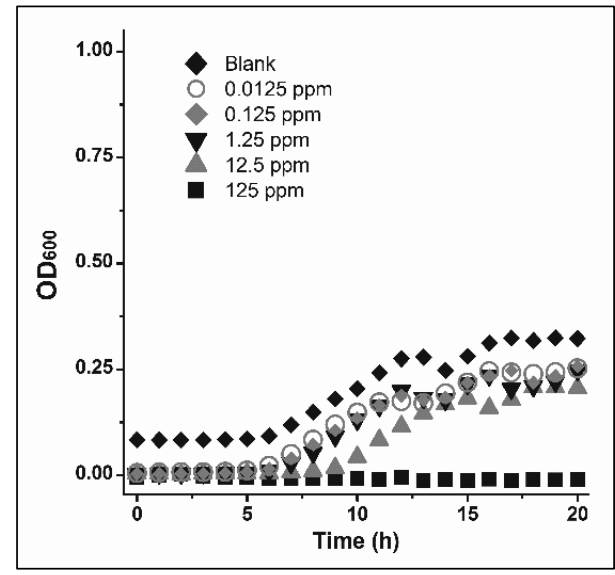

Figure 9. Antimicrobial effect of the AQM molecule on Bacillus sp. OD600 is optical density at $600 \mathrm{~nm}$. Each point presents the mean of three measurements. The SD bars were deleted for clarity.

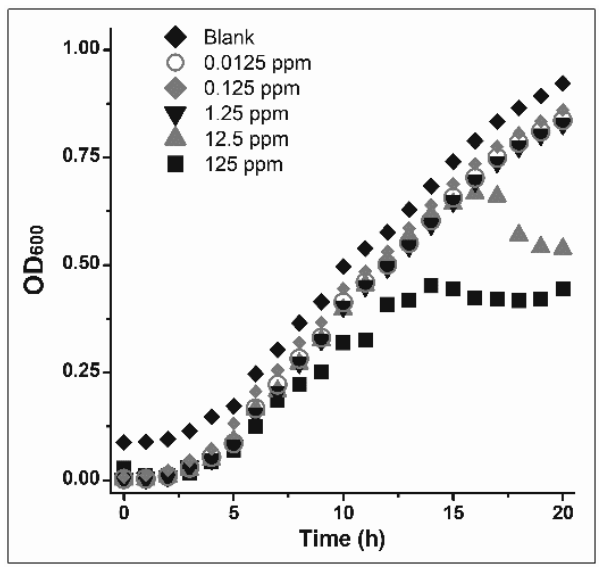

Figure 10. Antimicrobial effect of the AQM molecule on Pectobacterium carotovorum subsp. Carotovorum, Pcc. OD600 is optical density at $600 \mathrm{~nm}$. Each point presents the mean of three measurements. The SD bars were deleted for clarity.

The antibacterial rates (\%) of AQM against these bacteria are shown in Table 1. The DMSO concentrations tested shows no bacteriostatic or bactericidal effect against the bacterial strains. The antibacterial effect of AQM against $S$. aureus and Bacillus sp., but not against P. syringae, is a result similar to those previously reported in studies that compare the effect of a 2-alkyl-4-hydroxyquinoline (AHQ) against $S$. aureus and $P$. aeruginosa. Comparing our results with those reported in the aforementioned studies, it highlights the fact that both AQM and AHQ contain a quinoline ring substituted in 2- and 4-position and both molecules were applied to cultures of $S$. aureus and Pseudomonas. ${ }^{36}$ Although the biochemical explanation for the negative effect of AHQ on the growth of $S$. aureus is unknown, it has been suggested that its cell membrane is easily permeated by this molecule through passive diffusion, where it interferes with the electron transport chain, affecting cellular respiration, slowing cellular growth rate and inducing an extended Lag phase. On the other hand, these researchers argue that AHQ molecule is not able to penetrate $P$. aeruginosa due to the low permeability of its cell outer membrane and efficient elimination of antibiotics by means of efflux pumps, ${ }^{37-39}$ and therefore this bacteria remained unaltered. Other researchers demonstrated that some AHQs molecules (as well as its N-oxide derivative) biosynthesized by $P$. aeruginosa act as antiStaphylococcus agents, in similar way to commercial 4-quinolones, inhibiting genome replication by blocking topoisomerase enzyme activity. ${ }^{36}$ Therefore, since AQM has a similar chemical structure and biological activity to the AHQs, it probably use the same mechanism of action described above for AHQ

Table 1. The antibacterial activity (\%) of AQM against pathogenic bacteria $(\mathrm{n}=3$; mean $\pm \mathrm{SD})$. The experimental time was established to be $20 \mathrm{~h}$.

\begin{tabular}{|l|l|c|c|c|c|c|}
\hline Molecule & \multicolumn{1}{|c|}{ Bacteria } & \multicolumn{5}{|c|}{ Antibacterial Rate (\%) } \\
\hline & & $\mathbf{1 2 5} \mathbf{~ p p m}$ & $\mathbf{1 2 . 5} \mathbf{~ p p m}$ & $\mathbf{1 . 2 5} \mathbf{~ p p m}$ & $\mathbf{0 . 1 2 5} \mathbf{~ p p m}$ & $\mathbf{0 . 0 1 2 5} \mathbf{~ p p m}$ \\
\hline AQM & Bacillus sp. & $100.0 \pm 0.7$ & $36.3 \pm 1.4$ & $23.3 \pm 2.0$ & $20.2 \pm 5.5$ & $21.9 \pm 3.4$ \\
\hline AQM & S. aureus & $99.7 \pm 0.2$ & $33.7 \pm 5.6$ & $29.0 \pm 3.7$ & $30.8 \pm 2.9$ & $32.7 \pm 2.2$ \\
\hline AQM & Pcc & $51.7 \pm 2.1$ & $41.6 \pm 0.4$ & $10.1 \pm 1.9$ & $7.2 \pm 0.5$ & $9.3 \pm 3.0$ \\
\hline AQM & R. solanacearum ${ }^{a}$ & $17.3 \pm 0.6$ & $11.2 \pm 1.0$ & $9.9 \pm 1.0$ & $10.7 \pm 0.7$ & $10.5 \pm 1.5$ \\
\hline AQM & P. syringae & $16.7 \pm 3.7$ & $6.3 \pm 2.8$ & $7.9 \pm 4.8$ & $11.8 \pm 2.3$ & $7.2 \pm 3.0$ \\
\hline AQM & K. pneumoniae & $7.3 \pm 0.7$ & $4.6 \pm 1.2$ & $10.2 \pm 1.6$ & $10.1 \pm 0.6$ & $10.4 \pm 0.8$ \\
\hline
\end{tabular}

In addition to the presence of substituents at the 2- and 4-position of the quinoline ring of $\mathrm{AQM}$, the chlorine atom at 7-position of the ring is a common structural feature among some antimicrobial quinoline derivatives, ${ }^{13,14,27,40-42}$ which is essential in achieving antibacterial effect, according to de Souza et al. ${ }^{43}$ With respect to the AHQs, or their 2-alkyl-4-quinolone tautomeric forms, it is important to highlight that they are biosynthesized and extracellularly released by $P$. aeruginosa during its colonization mechanism in the presence of other competing bacteria, with the aim of inhibiting the growth of these latter.

AHQs also act simultaneously as cell-to-cell signaling molecules that lead to the formation of biofilms, and along with other similar molecules, including 2heptyl-3-hydroxy-4(1H)-quinolone (also known as the Pseudomonas Quinolone Signal, PQS), are part of the so-called "pseudanes". This name is derived from Pseudomonas, the bacterial genus in which such molecules were discovered, but they have also been found in bacteria of the genus Burkholderia, Alteromonas and Pseudonocardia..$^{37,44-46}$ Interestingly, like some "pseudanes" (e.g., PQS, AHQs), AQM is fluorescent and is quenched by interaction with ferric ion $\left(\mathrm{Fe}^{3+}\right),{ }^{47-49}$ as confirmed by fluorescence measurements performed in the present study (see Experimental Section). In addition, it is important to mention that: (1) ferric ion is one of the most important nutrients for bacteria, being essential for processes such as DNA replication, transcription, metabolism, and energy generation via respiration; and (2) the TSB medium used in the bioassays contains between 10 and $20 \mu \mathrm{M}$ of $\mathrm{Fe}^{3+, 50}$ therefore the following question arises: ¿Is antibacterial activity of AQM related to its ability to interact with $\mathrm{Fe}^{3+}$ ions in the culture medium, and if so, is it works similar to some bacterial siderophores or competing siderophore? Although no additional experiments were performed in this study to attempt to answer this question, it is important to highlight that the bacteria most affected by AQM were the Gram-positive $S$. aureus and Bacillus sp., while the Gram-negative bacteria remained unaffected (except $P c c$, which is moderately affected). One possible explanation for the latter observation is that the Gram-positive bacteria exhibit relatively few iron-uptake mechanisms compared to Gram-negative bacteria (which are recognized by their diversity of highly efficient mechanisms of siderophore-mediated iron uptake), ${ }^{51,52}$ this prevents Gram-positive bacteria from effectively competing for iron in the presence of other synthetic competing chelators, and according to our results most probably AQM is one competing iron-chelator (Figures 3 and 4). These results open the door to future studies to evaluate the potential effect of AQM on the iron uptake process in Gram-positive bacteria. 


\section{CONCLUSIONS}

The following conclusions were drawn: (1) The compound AQM exhibited bacteriostatic effect on $S$. aureus and Bacillus $s p$., and was not active on the Gram-negative bacteria ( $R$. solanacearum, $K$. pneuminiae, and $P$. syringae) except for Pcc whose growth rate decreased moderately $(51.7 \%)$. (2) The fluorescence quenching of $\mathrm{AQM}$ by the addition of $\mathrm{Fe}^{3+}$ ion, suggests the formation of a non-fluorescent stable complex with $\mathrm{Fe}^{3+}$ ion, and consequently, this synthetic iron chelator (AQM) probably competed with the siderophores of both Gram-positive bacteria, leading to bacterial growth inhibition. These results show the potential use of AQM as new drug in antibacterial therapy or in the fluorometric detection of $\mathrm{Fe}^{3+}$ ions.

\section{ACKNOWLEDGMENTS}

H. Valle and L. Aguilar thanks the support from the Comisión Nacional de Investigación Científica y Tecnológica (CONICYT), Chile, through the projects CONICYT/FONDECYT postdoctoral $\mathrm{N}^{\circ} 3160296$ and CONICYT/FONDAP/15130015, respectively.

\section{REFERENCES}

1. S. M. A. Hussaini, Expert Opin. Ther. Pat. 26, 1201 (2016).

2. A. Marella, O. P. Tanwar, R. Saha, M. R. Ali, S. Srivastava, M. Akhter, M. Shaquiquzzaman, and M. M. Alam, Saudi Pharm. J. 21, 1 (2013) .

3. C.-H. Lee and H.-S. Lee, J. Korean Soc. Appl. Biol. Chem. 52, 331 (2009).

4. M. Artico, A. Mai, G. Sbardella, S. Massa, C. Musiu, S. Lostia, F. Demontis, and P. La Colla, Bioorganic Med. Chem. Lett. 9, 1651 (1999).

5. G. S. Bisacchi, J. Med. Chem. 58, 4874 (2015).

6. R. Cherdtrakulkiat, S. Boonpangrak, N. Sinthupoom, S. Prachayasittikul, S. Ruchirawat, and V. Prachayasittikul, Biochem. Biophys. Reports 6, 135 (2016).

7. V. Prachayasittikul, V. Prachayasittikul, S. Prachayasittikul, and S. Ruchirawat, Drug Des. Devel. Ther. 7, 1157 (2013).

8. M. Asif, Ann Med Chem Res 1, 1003 (2014).

9. M. A. Kohanski, D. J. Dwyer, and J. J. Collins, Nat. Rev. Microbiol. 8, 423 (2010).

10. V. Uivarosi, Molecules 18, 11153 (2013).

11. C. Pelletier, P. Prognon, and P. Bourlioux, Antimicrob. Agents Chemother. 39, 707 (1995).

12. H. Huber-Emden, A. Hubele, and G. Klahre, Patent US3873703A, 1975.

13. D. Ghisalberti, A. Mahamoud, J. Chevalier, M. Baitiche, M. Martino, J.-M. Pagès, and J. Barbe, Int. J. Antimicrob. Agents 27, 565 (2006).

14. J.-M. Rolain, P. Colson, and D. Raoult, Int. J. Antimicrob. Agents 30, 297 (2007).

15. A. So, B. A. Nacev, C. R. Chong, H. C. Bhang, J. Xu, J. S. Shim, J. O. Liu, K. C. Han, M. G. Pomper, S. Bhat, S. Dhara, and Y. Matsui, JNCI J. Natl. Cancer Inst. 102, 1855 (2010).

16. B. Mirković, B. Markelc, M. Butinar, A. Mitrović, I. Sosič, S. Gobec, O. Vasiljeva, B. Turk, M. Čemažar, G. Serša, and J. Kos, Oncotarget 6, 19027 (2015).

17. J. Lazovic, L. Guo, J. Nakashima, L. Mirsadraei, W. Yong, H. J. Kim, B. Ellingson, H. Wu, and W. B. Pope, Neuro. Oncol. 17, 53 (2014).

18. W.-L. Chang, L.-C. Hsu, W.-J. Leu, C.-S. Chen, and J.-H. Guh, Oncotarget 6, 39806 (2015).

19. V. Prachayasittikul, W. Chan-On, H. Nguyen Thi Bich, N. Songtawee, W. Suwanjang, and S. Prachayasittikul, Drug Des. Devel. Ther. 9, 2033 (2015).

20. H. Jiang, J. E. Taggart, X. Zhang, D. M. Benbrook, S. E. Lind, and W.-Q. Ding, Cancer Lett. 312, 11 (2011).

21. P. Huang and Q. Li, Patent WO 2017/173278 A1, 2017.

22. M. Fiorillo, R. Lamb, H. B. Tanowitz, A. R. Cappello, U. E. MartinezOutschoorn, F. Sotgia, and M. P. Lisanti, Aging (Albany. NY). 8, 1593 (2016).

23. P. Pantziarka, V. Sukhatme, L. Meheus, V. Sukhatme, and G. Bouche, BioRxiv 197434 (2017).

24. Q. Dong, J. Luo, W. Qiu, L. Cai, S. Anjum, B. Li, M. Hou, G. Xie, G. Sun, Q. Dong, J. Luo, W. Qiu, L. Cai, S. I. Anjum, B. Li, M. Hou, G. Xie, and G. Sun, Molecules 21, 978 (2016).

25. H. Valle, R. Palao-Suay, M. R. Aguilar, J. S. Román, J. Becerra, B. Rivas, and R. V. Mangalaraja, J. Appl. Polym. Sci. 136, 47545 (2019).

26. CLSI, Methods for Dilution Antimicrobial Susceptibility Tests for Bacteria That Grow Aerobically (CLSI Document M07-A9), Approved Standard 9th Ed. (Clinical and Laboratory Standards Institute, Wayne, Pennsylvania, 2012), pp. 16-20.
27. S. Singh, K. K. Roy, S. R. Khan, V. K. Kashyap, A. Sharma, S. Jaiswal, S. K. Sharma, M. Y. Krishnan, V. Chaturvedi, J. Lal, S. Sinha, A. Dasgupta, R. Srivastava, and A. K. Saxena, Bioorg. Med. Chem. 23, 742 (2015).

28. I. J. Pachter, J. Am. Chem. Soc. 75, 3026 (1953).

29. A. Esparza-Ruiz, C. Herrmann, J. Chen, B. O. Patrick, E. Polishchuk, and C. Orvig, Inorganica Chim. Acta 393, 276 (2012).

30. *B. Valeur and M. N. Berberan-Santos, Molecular Fluorescence : Principles and Applications, 2nd Ed. (Wiley-VCH, Weinheim, 2012), pp. 72-74.

31. D. S. Karpovich and G. J. Blanchard, J. Phys. Chem. 99, 3951 (1995).

32. Y. W. Choi, G. J. Park, Y. J. Na, H. Y. Jo, S. A. Lee, G. R. You, and C. Kim, Sensors Actuators B Chem. 194, 343 (2014).

33. X. Bao, X. Cao, X. Nie, Y. Xu, W. Guo, B. Zhou, L. Zhang, H. Liao, and T. Pang, Sensors Actuators B Chem. 208, 54 (2015).

34. P. Kaur, H. Kaur, and K. Singh, RSC Adv. 3, 64 (2013).

35. X. Yang, P. Zhao, J. Qu, and R. Liu, Luminescence 30, 592 (2015).

36. Z. A. Machan, G. W. Taylor, T. L. Pitt, P. J. Cole, and R. Wilson, J. Antimicrob. Chemother. 30, 615 (1992).

37. F. Salvaggio, J. T. Hodgkinson, L. Carro, S. M. Geddis, W. R. J. D. Galloway, M. Welch, and D. R. Spring, European J. Org. Chem. 434 (2016).

38. P. A. Lambert, J. R. Soc. Med. 95 Suppl 4, 22 (2002).

39. J. Ruiz, J. Antimicrob. Chemother. 51, 1109 (2003).

40. R. Clinton and C. Suter, Patent US2505462A, 1950.

41. M. Rudrapal and D. Chetia, Int. J. ChemTech Res. 2, 1606 (2010).

42. R. Jagadeesh, K. N. Saivisveswar, and S. P. Revankar, Sch. J. App. Med. Sci. 2, 3046 (2014).

43. M. V. N. de Souza, K. C. Pais, C. R. Kaiser, M. A. Peralta, M. de L. Ferreira, and M. C. S. Lourenço, Bioorg. Med. Chem. 17, 1474 (2009).

44. M. Toyofuku, T. Nakajima-Kambe, H. Uchiyama, and N. Nomura, Microbes Environ. 25, 1 (2010).

45. S. Heeb, M. P. Fletcher, S. R. Chhabra, S. P. Diggle, P. Williams, and M. Cámara, FEMS Microbiol. Rev. 35, 247 (2011).

46. H. Budzikiewicz, Siderophores of the Pseudomonadaceae sensu stricto (Fluorescent and Non-Fluorescent Pseudomonas spp.), in Progress in the Chemistry of Organic Natural Products, ed. by W. Herz, H. Falk, and G. W. Kirby (Springer Vienna, Vienna, 2004), p. 81.

47. S. P. Diggle, S. Matthijs, V. J. Wright, M. P. Fletcher, S. R. Chhabra, I. L. Lamont, X. Kong, R. C. Hider, P. Cornelis, M. Cámara, and P. Williams, Chem. Biol. 14, 87 (2007).

48. P. W. Royt, R. V. Honeychuck, V. Ravich, P. Ponnaluri, L. K. Pannell, J. S. Buyer, V. Chandhoke, W. M. Stalick, L. C. DeSesso, S. Donohue, R. Ghei, J. D. Relyea, and R. Ruiz, Bioorg. Chem. 29, 387 (2001).

49. G. Palmer, J. Schertzer, L. Mashburn-Warren, M. Whiteley, Methods Mol. Biol. 692, 207 (2011).

50. W. Raza, W. Hongsheng, and S. Qirong, Brazilian Arch. Biol. Technol. 53, 1145 (2010)

51. F. Imperi, K. A. Mettrick, M. Shirley, F. Tiburzi, R. C. Draper, P. Visca, and I. L. Lamont, Iron Transport and Signaling in Pseudomonads, in Pseudomonas, ed. by B. H. Rehm (Wiley-VCH Verlag GmbH \& Co. KGaA, Weinheim, Germany, 2008), p. 129.

52. J. S. Brown and D. W. Holden, Microbes Infect. 4, 1149 (2002). 